\title{
A PSICO-MORFOLOGIA DA EXPERIÊNCIA SOCIAL: DA ATOMIZAÇÃO DA PRIVACIDADE À INTIMIDADE PÚBLICA ${ }^{1}$
}

\author{
PSYCHOMORPHOLOGY OF SOCIAL EXPERIENCE: FROM THE
}

ATOMIZATION OF PRIVACY TO PUBLIC INTIMACY

PSICO-MORFOLOGÍA DE LA EXPERIENCIA SOCIAL: DE LA

ATOMIZACIÓN DE LA PRIVACIDAD À LA INTIMIDAD PÚBLICA

Samuel Mateus

Professor Auxiliar, Universidade da Madeira

samuelmateus@uma.pt

\begin{abstract}
Resumo
Personalidade, Privacidade e Intimidade são noções basilares da experiência social. Acompanhando estes conceitos ao longo dos últimos séculos, o presente artigo procura analisar o investimento psicológico, orientado para a privacidade, da individualização moderna comparando-o com a experiência contemporânea.

Será argumentado que, dada a centralidade dos dispositivos tecnológicos de mediação simbólica, e em especial as redes sociais online, a individualização hodierna assenta num investimento pessoal que já não faz da intimidade e da privacidade as suas dimensões fundamentais mas que é justamente uma certa publicização do privado, e um certo movimento de mostração da intimidade que constituem os seus principais atributos.
\end{abstract}

Palavras-Chave: Experiência Social; Intimidade e Privacidade; Media Sociais;

\begin{abstract}
Personality, privacy and intimacy are vital notions of social experience. Examining these concepts over the past centuries, this paper seeks to analyze the psychological investment on privacy of modern individualization, and compares it to contemporary experience.

It will be argued that, given the centrality of media, especially online social networks, contemporary individualization is based on a personal investment that no longer makes the intimacy and privacy its fundamental dimensions, but that it is precisely a certain publicization of privacy, and a certain display of intimacy that constitute its main attributes.
\end{abstract}

Key-words: Publicity and Privacy; Individualization; Intimacy; Digital Social Networks;

\section{Resumen}

Personalidad, privacidad e intimidad son nociones fundamentales de la experiencia social. Acompañando estos conceptos en los últimos siglos, este artículo pretende analizar la

\footnotetext{
${ }^{1}$ Uma versão desta reflexão foi apresentada no II Congresso Confibercom, em Fevereiro de 2014.
} 
inversión psicológica, orientada a la privacidad, de la individualización moderna comparándolo con la experiencia contemporánea.

Se argumentó que, dada la centralidad de dispositivos tecnológicos de mediación simbólica, en particular las redes sociales en línea, la individualización hoy en día ya no hace de la intimidad y privacidad las dimensiones principales, sino que es sólo una cierta publicación de lo privado y un cierto movimiento de demostración de la intimidad que constituyen sus principales atributos.

Palabras clave: Experiencia Social; Intimidad y Privacidad; Media Sociales;

Esta obra está licenciada sob uma Licença Creative Commons

\section{Introdução}

A privacidade afigura-se como um pólo dominante da vida social. A própria ideia moderna de indivíduo vai a par com a noção de privacidade. Na Idade Média, a diferenciação idiossincrática não podia ser objecto senão de uma marginalidade, depreciação e contestação social. Era na colectividade que o espírito do homem se nutria; todo o isolamento seria remetido para o domínio do estranho uma vez que denota um desvio dos papéis socialmente aceites. O louco, a bruxa e o eremita são encarnações dramáticas do homem que se subtrai às redes colectivas de controlo do Senhor Feudal ou da Igreja e que por isso são relegados social e religiosamente ao degredo. $\mathrm{O}$ eremita monástico era o único homem a quem se permitia destacar-se (isto é, desarticular) da comunidade e desfrutar de algum sentimento de privacidade, porque a "Regra de S. Bento" previa um grau superior de perfeição na devoção solitária do monge, afastado das tentações corpóreas do mundo exterior à abadia. Alias, a experiência monástica foi uma das primeiras formas arcaicas da privacidade tendo dado um dos primeiros impulsos à individualização que a modernidade consagraria.

É no séc. XIX que se reacentua do papel da privacidade na sociedade ao mesmo tempo que a publicidade é desinvestida da dimensão convivial e de uma sociabilidade concreta. Numa sociedade estandardizada - a de uma sociabilidade predominantemente de massa com uma vasta população anónima - o homem coloca-se ao abrigo dos olhares, e isto de duas formas.

Em primeiro lugar, por uma reivindicação da individualidade iniciada com o Renascimento e consagrada durante o Iluminismo, e do direito de deliberar sobre a sua própria vida por intermédio de um projecto reflexivo do self. O recrudescimento dos nomes pessoais, a preferência por túmulos individuais, a valorização do corpo assinalada pela higiene íntima e a separação dos leitos, são fenómenos históricos sintomas desse processo de identidade individual (Corbin, 1985). 
Em segundo lugar, o homem recata-se dos outros através de um investimento pessoal na esfera doméstica e familiar encarada agora como refúgio e âmago da privacidade (Habermas, 1991: 43-51). A família adquire novos e originais contornos. Ela já não é um constrangimento da liberdade como no modelo helénico (Arendt, 2001), nem apenas uma unidade económica de reprodução material como no modelo burguês de publicidade (Habermas, 1991). A família ganha nuances nunca antes registados: a de ser um lugar antitético do mundo exterior onde a emergente interioridade individual pode repousar das agruras que o contacto anónimo e impessoal pode causar. Ela configura-se como lugar de afectividade onde a sentimentalidade pode realizar-se plenamente, tanto ao nível do casal, como ao nível parental. A valorização da infância como etapa distinta da idade adulta encontra neste entendimento da domesticidade a sua nascente. Por outro lado, o lema "home, sweet home" atesta exemplarmente a associação entre a esfera doméstica e a esfera privada sendo o lar o ideal de privacidade .

As fundas poltronas, as franjinhas rendilhadas dos banquinhos, os grossos tapetes, os pesados cortinados, a profusão de espelhos e retratos formam os acessórios domésticos que qualificam a privacidade como o lugar de referência do indivíduo que encontra aí o reino de autoconfirmação e afirmação. É mesmo na apologia da privacidade que no Séc. XIX é criada uma nova categoria social: a dona-de-casa. Ela é o centro da esfera doméstica, desse mundo do indivíduo dobrado sobre si mesmo que recebe o encargo de manter coesa a família e de ser uma espécie de alma da domesticidade, vigiando todos os aspectos que façam do lar o espaço privado reconfortante por excelência.

Ao assumir este papel, a família não apenas absorve o indivíduo recolhendo-o e providenciando-lhe uma ancoragem firme para a personalidade, como também, o separa da esfera pública com o qual o indivíduo até aí estava em permanente contacto.

Não deixa de ser curioso e paradoxal a privacidade ser um fundamento do público como defende Habermas (1991) - e simultaneamente um seu inibidor, como veremos de seguida.

\section{A Desmolecularização do Público e do Privado}

Poderá dizer-se que público e privado são conceitos moleculares, dois modos humanos de expressão correlativos e correlacionados. Na verdade, a qualidade pública e a qualidade privada não são estados fixos e cristalizados; constituem, antes, processos sociais fluidos e amplos, duas formas de experiência social e dois modos de percepção fenomenológica do mundo. A sua oposição ab ovo caracteriza-se pela transversalidade ao tecido social e pela sua 
articulação mais ou menos subtil, mais ou menos próxima. Em última análise, público e privado definem-se dialecticamente pela oposição diferencial: o privado como sendo aquilo que o público não é.

Porém, na modernidade a molécula tende a quebrar-se. A demarcação entre o idion e o koinon, entre o idiossincrático e o comum, se quisermos, entre a ocultação e a revelação esbate-se e como ela a essência da vida humana e a consequente mutação na valorização do indivíduo. Privado e público atomizam-se no momento em que a personalidade e o carácter se instituíram como princípios sociais, fenómenos que já se havia iniciado com a procura da liberdade pessoal do Séc. XVIII (Sennett, 1974: 99).

O público desaparece do horizonte do privado assim como o privado deixa de assentar na mesma lógica comunitária do público. Cada átomo prossegue diferentes direcções adquirindo autonomia em relação ao outro.

Duas causas principais da quebra molecular entre público e privado (Sennett, 1974:1924) podem ser apontadas. Um factor seguramente determinante foi a organização económica sob o modelo do capitalismo industrial e o ordenamento urbano da vida social. A estandardização dos bens e serviços, inclusivamente a indumentária, acentua uma uniformidade na apresentação pública de si que faz o indivíduo carecer de marcas distintiva externas. A personalidade é aí o atributo fundamental de diferenciação social e intersubjectiva e para tal, foi o privado que recebeu a primazia como modo de escapar à padronização. Os produtos industriais e o que mais tarde se apelidou de bens de consumo revelaram-se centrais no desenvolvimento de uma ideia de personalidade e essência interior e foi justamente nessa direcção que os anúncios comerciais apontaram as suas estratégias de vendas. O indivíduo para o ser deve cuidar de si, deve apresentar-se como pessoa especial e única, e para tal recebe do capitalismo industrial toda uma parafernália de acessórios, objectos e dispositivos de comunicação que fazem da esfera privada a origem da sua distinção.

Um segundo factor envolvido na desmoleculalização do público e do privado, e que modificou a vida pública herdada do Ancien Régime, foi a transformação dos modos interpretativos da vida quotidiana. A secularização, opondo-se ao sagrado, trouxe um princípio de funcionamento imanente em oposição ao transcendente. A realidade, o facto, a sensação que cada uma experimentava instantaneamente, no aqui e agora, e fora de esquemas pré-fixos tornou-se a nova medida e obteve enormes efeitos na publicidade. Ao introduzir a crença de que as coisas possuem um significado intrínseco então o que está em causa é uma nova maneira de interpretar a vida pública. Esta passa a ser entendida na associação exclusiva ao indivíduo que identifica nela a oportunidade de definir a sua própria identidade. Esta torna- 
se, sobretudo, uma encenação dramática da personalidade, uma apresentação de si no quotidiano que reveste o indivíduo de uma persona, uma máscara (Sennett, 1974: 153).

O indivíduo passa a ser avalizado como pessoa, ou seja, enquanto composto de multiestratos que ressoam orquestradamente na definição de uma personagem e de um carácter. $\mathrm{O}$ que acarreta um risco inerente: se o indivíduo se compõe na retumbância de estratos de carácter (como se exemplifica actualmente na escolha de nicknames ou avatares em chats virtuais e aplicações de internet) o desfolhar de cada pode fazer que, tal como numa cebola, não sobre nada. No salto diletante entre personas e entre funções sociais que o indivíduo necessita corresponder é a sua dissociação e a sua alienação que se joga. Mas é especialmente um outro aspecto que a literatura de civilidade já havia prognosticado: o indivíduo acaba por recear desnudar-se e trair a sua essência e a sua personalidade. Desse modo, ele retrai-se, de actor passa a espectador, de espectador activo e barulhento transforma-se num observador perdido na escuridão da sala, silencioso, comedido e invisível (Sennett, 1974: 205).

A repressão sentimental agudiza-se numa sociedade anónima e urbanizada onde o tempo da interacção com estranhos supera enormemente aquele passado na família. $\mathrm{O}$ individuo é simbolizado pelo flânneur, o homem indolente expectante, observador- voyeur que se abstém de participar e que não se retirando da sociedade se ausenta dela. A janela (de televisão ou de cinema) são os símbolos dessa observação despreocupada e frívola que permite ver sem ser visto, conhecer sem participar, estar presente na ausência. $\mathrm{O}$ espreitar ou o perscrutar, próprio da observação pela janela, comungam das duas dimensões do privado e do público: por um lado intervém passiva e discretamente no espaço público exterior ao lar doméstico; mas ao mesmo tempo o indivíduo permanece resguardado e protegido pelos muros da privacidade que lhe permite aceder ao público sem se revelar ou aparecer, preservando da decomposição a sua personalidade.

\section{A Personalidade como Categoria Social}

Decorrente desse processo ocorre, em finais do séc. XIX prologando-se em todo o séc. XX, uma desvitalização da publicidade e um hiper-investimento na esfera privada. Uma alma (psyche) que anima o indivíduo de modo ímpar, uma vida interior que se dá a ver num padrão de tendências reactivas de pensamento, comportamento e sentimento a que se chama personalidade inaugura o homo psychologicus. A vida psíquica é tratada como preciosa e delicada devendo ser preservada na vida pública sob pena de não se desenvolver em plenitude. Assim, a feitura da personalidade torna-se uma das grandes responsabilidades que o 
indivíduo moderno assume: tarefa de Sísifo, em que todos os dias deve guardar a sua interioridade dos riscos do mundo exterior. A personalidade obriga a que a sua protecção seja sempre ser reposta e reerguida para que a singularidade do indivíduo não pereça, numa verdadeira reconquista da verdade do "eu" numa atitude de self-examination .

Para tal, o indivíduo desenvolve na sua vida um questionamento da sua personalidade para encontrar a sua genuinidade como se fosse um garimpeiro: depurando e peneirando as inconsistências quotidianas, fragmentando e separando os sólidos factos que se vão sedimentando sob o curricula do indivíduo. Porém, este conhecimento do indivíduo está nos antípodas do adágio que o oráculo de Delfos recomendou a Sócrates, o Gnothi Seauton (“conhece-te a ti mesmo"). Neste caso o conhecimento do homem é filosófico e reflectivo procedendo à anamnese, o objectivo primário de qualquer especulação e que deve presidir a qualquer inquérito - introspectivo, maiêutico ou dialéctico. O conhece-te a ti mesmo da modernidade, porém, é um fim em si mesmo, não ambiciona ser um meio para conhecer o mundo. E por esse facto autoanula-se porque nessa absorção absorta da personalidade movida pelo indivíduo, ele só pode ver os outros pelas lentes desfocadas de si próprio.

$\mathrm{Na}$ modernidade, a atomização do privado fez da personalidade o último reduto do indivíduo e toda a experiência social só é apreendida se convertida num grande sistema psíquico: o mundo psico-morfologiza-se (Sennett, 1974: 259) (Lipovetsky, 1989: 15) . A personalidade torna-se uma categoria social e consiste na subjectivação das actividades sociais. Não é por acaso que foi no séc. XIX que nasceu a Psiquiatria, a Psicologia, a Psicanálise a Psicognosia, a Psicografia ou o Psico-drama. O "calor humano" e a proximidade tornam-se bens morais e não é raro ocorrerem verdadeiras psicalgias. A personalidade obriga o indivíduo a assumir-se como refugiado: um refugiado da publicidade que encontra na esfera privada o culto de si mesmo.

Ao contrário do Ancien Regime, a experiência pública não visa a formação de uma ordem social mas antes conecta-se à formação da personalidade. $\mathrm{O}$ culto do self passou a definir as relações sociais e tornou-se um dos princípios de funcionamento social.

\section{A Intimidade Moderna}

É assim que personalidade e sociabilidade se tornam tendências hostis. A expressão pública tende, por isso, a retrair-se. À ordem social associa-se a ausência de interacção e o silêncio. Por isso, em 1840, a prática de beber álcool é bem-vista ao impedir a prática 
discursiva e os tumultos sociais potencialmente decorrentes da sociabilização dos trabalhadores (Sennett, 1974: 214).

Esta angústia psíquica advinda da consagração da personalidade como princípio regulador da sociedade abriu caminho à instituição de uma nova categoria: a de intimidade, a qual abarcará toda a esfera privada. Se o Séc. XVIII foi o do público, o Séc. XIX, o do privado, o Séc. XX talvez possa ser visto como o centénio da intimidade .

A intimidade define-se na exacerbação da privatização e da "queda do homem público" (Sennett, 1974) e deve em concomitância ser entendida como "o desejo do indivíduo retirar do controlo do mundo externo certas experiências e de fazer valer a sua pretensão de as considerar como exclusivamente próprias" (Mannheim, 1978: 212). Na sua radicalização das inclinações da privacidade, a intimidade configura-se como um intenso culto do indivíduo, como se este com a secularização fosse uma nova religião, como advertiu Durkheim.

Arendt (2001) e Habermas (1991) associam o nascimento da intimidade com o aparecimento, no séc. XIX, de respectivamente uma Esfera Social e um Estado-Providência, os quais reclamam para o domínio público funções privadas. O Estado -Providência fará com que a família perca funções produtivas em prol de funções de consumo que, juntamente com a perca de posse de propriedade por parte da família, passa a estar sob alçada Estatal. A esfera privada concentra-se e encolhe-se sobre a família conjugal que faz de si mesma o núcleo fundamental da privacidade originando o que chamamos de intimidade. Esta é, assim, um verdadeiro asilo, caixa-forte do indivíduo que não abdica de ser a herdeira da privacidade. Dirige-se, em primeiro lugar, contra as exigências niveladoras do social que se manifestam sob a forma do conformismo, facto que com a sociedade estandardizada se acometeu como mesmo vigor sobre todos os seus membros. O íntimo expressa o carácter recôndito, profundo, secreto e interior do homem. " A moderna descoberta da intimidade parece constituir uma fuga do mundo exterior como um todo para a subjectividade interior do indivíduo, subjectividade esta que antes fora abrigada e protegida pela esfera privada" (Arendt, 2001: $82)$.

A importância que a intimidade adquire na modernidade é confirmada pela sua consignação jurídica sendo considerada parte integrante dos direitos de personalidade que se materializam no direito de excluir terceiros dos assuntos pessoais. $\mathrm{O}$ direito à intimidade corporaliza-se, por exemplos, na inviolabilidade do domicílio, passa pelo sigilo postal, pelo segredo profissional até ao direito à honra e à boa reputação .

A intimidade restituiu-se no Séc. XX como aspiração, mito e crença primordial tanto da sociedade como do indivíduo. É uma ideologia que postula a credibilidade e autenticidade 
das relações sociais na proximidade à sinceridade pessoal. Refúgio dos constrangimentos que ultrapassam o homem, âmago da personalidade, morfologia da experiência social. Contudo, existe uma ameaça enorme. Enquanto se tentam fomentar as solidariedades como meio de destruição da impessoalidade, foge a oportunidade de cultivar um projecto comum. " Um modo de agir que recusa negociar e de uma contínua expurgação dos estranhos resulta do suposto desejo humanitário de apagar a impessoalidade das relações sociais. E na mesma medida este mito da impessoalidade é auto-destrutivo. A prossecução do interesse comum é destruída pela busca da identidade comum" (Sennett, 1974: 261). Ao tornar-se intimista, a sociedade arrisca a não criação de dialogismos.

Nesta medida, a intimidade toma laivos de tirania, um princípio déspota que cataloga as rotinas de sociabilidade de acordo com a superficialidade e efemeridade. Como princípio dominante das sociedades ocidentais do Séc. XX, a intimidade representa, de certa forma, uma opressão ao ofuscar outros modos de aferição do indivíduo e da sociedade. O indivíduo sente como "desmaiado" tudo aquilo que não corresponde a um sentimento interior, singular e especial. A essência da civilidade é justamente o uso de uma persona, uma máscara que permita a interacção entre estranhos anónimos e que torna previsíveis os comportamentos de como que se desfrute da companhia mútua sem causar susceptibilidades ou impertinências .

É justamente uma possibilidade de criação pública de personas ou avatares que os dispositivos tecnológicos de mediação simbólica, sobretudo a internet e as redes sociais online, possibilitam ao indivíduo contemporâneo.

Como veremos na próxima secção, eles vieram transformar a psico-morfologia da experiência social configurando a intimidade de modo absolutamente diferente.

\section{Os Media e a Intimidade Contemporânea}

A passagem do séc. XX para o séc. XXI trouxe consigo a consolidação de um conjunto de tecnologias da informação e da comunicação que alteraram por completo o equilíbrio da experiência social no que à privacidade e à intimidade dizem respeito.

Mesmo um media de sucesso como a televisão reformularam os seus conteúdos programáticos inaugurando "novos" géneros televisivos como o reality-show (cf. Mateus, 2012). Géneros programáticos pós-modernos associados com novas aplicações e a massificação de gadgets tecnológicos como smartphones, tablets, ou a internet, vieram alterar as ideias modernas de personalidade e intimidade no momento em que trazem ambientes comunicacionais públicos para a esfera da privacidade. Actualmente é possível ter uma discussão com um conjunto de diferentes pessoais a partir do recato do sofá de casa, bastando 
para isso ter uma ligação de internet. Pode-se mesmo usar o telemóvel para participar socialmente em abaixo-assinados, petições e outras iniciativas de mobilização social, como por exemplo, as flashmobs. Os novos dispositivos tecnológicos de mediação simbólica, justamente com as suas aplicações inovadoras (como a rede social Twitter) definem, assim, um conjunto de oportunidades, não apenas de mobilização colectiva, como também de acesso à publicidade.

Aquilo que Sennett (1974: 264) identificou, no séc. XIX e XX, como a extinção do palco encenatório público face ao predomínio de uma sociedade intimista, não parece confirmar-se nas sociedades contemporâneas. O que, por exemplo, as redes sociais online como o MySpace ou Facebook, ilustram é precisamente o ressurgimento desse espaço de afirmação pública das personalidades e a necessidade que o indivíduo possui em divulgar, mostrar, e ostentar a sua vida privada, as suas inquietações quotidianas mas também os seus momentos felizes. Deste ponto de vista, a vida íntima perde o seu carácter insular e tirânico assumindo-se mais como um mecanismo flexível e articulável que os indivíduos modelam consoante a sua maior ou menor necessidade de reconhecimento social (Mehl,1996: 159).

Para o individualismo do séc. XIX e XX, o self é real somente se for contínuo; e tal só é conseguido se praticar uma permanente negação de si mesmo, isto é, ao afastar-se do contacto humano e da revelação da sua personalidade (Sennett, 1974: 335). No fundo, a sociedade intimista de cariz narcísico explana-se nos valores fundamentais da realização pessoal e da auto-determinação e no direito do indivíduo ser aquele que deseja ser (Bauman, 2000: 31). O narcisismo corresponde, por conseguinte, à "descrispação dos temas políticos e ideológicos e ao sobre-investimento concomitante das questões subjectivas" (Lipovetsky, 1989: 14).

A grande novidade que hoje é vivida é que essa auto-determinação é feita socialmente em dispositivos tecnológicos de mediação simbólica, nos quais o narcisismo hodierno envolve uma dimensão alardeadora que tem a ver a exposição da personalidade. A psicomorfologia e a sua ênfase nas ideias de personalidade e de intimidade continuam a ser traços marcantes da experiência social contemporânea. Contudo, o investimento pessoal que o indivíduo pósmoderno é agora um que se caracteriza pela mediatização da privacidade.

A sobreexposição de si empreendida aponta ainda para uma certa forma de individualismo; mas indica igualmente uma redefinição do horizonte da intimidade e da personalidade por intermédio dos novos dispositivos tecnológicos de comunicação. A psicomorfologia da experiência social permanece parece agora assentar numa exposição pública de si, num movimento de publicização do privado realizado através de dispositivos 
tecnológicos de mediação simbólica (Mateus, 2010). O investimento emocional que o indivíduo faz em si extravasa, nas sociedades contemporâneas, as fronteiras da intimidade e da privacidade para inundar o domínio público. É nesse movimento de exteriorização psicológica que a intimidade se torna pública (cf. Jost, 2009: 46). Esta vontade de exibição de si (Tele-Realidade (cf. Mateus, 2013) e especialmente programas como Big Brother), de mostração das emoções e sentimentos individuais na televisão (talk-shows), esse imperativo de ostentação da sua imagem (Facebook, Instagram) é a face mais evidente da reivindicação dos indivíduos a paradoxalmente se apropriarem da sua existência através da sua partilha.

Confissões, testemunhos, representações, experimentações da aparência, todas elas pululam nos media num movimento de revelação pública da privacidade e intimidade que Tisseron chamou de "extimidade" (Tisseron, 2001: 47). O direito à intimidade configura-se nesta emergência dos new media e networked media como uma verdadeira partilha da intimidade com um grande número de pessoas. O espaço intimo alarga-se e torna-se algo perfeitamente comunicável e distribuído. A "extimidade" designa, assim, esse movimento de sobre-exposição individual e na qual a sua personalidade e as suas emoções mais íntimas se tornam, na vida quotidiana, objecto de divulgação alargada. Assim, o que é importante nas redes sociais online, bem como na maioria dos reality-shows, é a possibilidade de oferecerem aos indivíduos uma forma de individualização colectiva ao tornarem públicos aspectos (físicos e psicológicos) que até aí permaneciam exclusivamente confinados à intimidade. Assim, a extimidade confere ao indivíduo comum uma maneira mediatizada de se exprimir em toda a sua singularidade. Ela exemplifica o super- investimento psicológico iniciado no séc. XIX, mas ao invés de o operar na penumbra do privado, esse investimento é agora realizado no Espaço Público por intermédio dos mais variados dispositivos tecnológicos de mediação simbólica.

Não parece, então, confirmar-se como absolutamente rigoroso o diagnóstico negativo do séc. XX: apesar de reclinado sobre a interioridade, o homem contemporâneo absorvido pelo íntimo e comungando da maldição de Narciso quer, apesar de tudo, ser afectado pelo outro. A psicologização social ultrapassa a mera privacidade e a intimidade para abranger os processos de socialização. Conversar, trocar impressões, distrair-se, são hoje actividades que o individuo realiza, por exemplo, no Orkut. A transparência de si, a sujeição de si e da sua aparência ao juízo dos seus pares, eis um modo singular de afirmação pessoal.

O que sobressai nos perfis públicos dos seus utilizadores é justamente um investimento psicológico em si e na sua personalidade. Porém, esse investimento é agora intensamente publicizado e partilhável num processo de individualização que é completado 
em concomitância com os outros e as suas próprias opiniões. A forte exposição fotográfica aí operada sublinha igualmente o quanto a psicologia individual necessita de ser reconhecida, encontrando na palavra cibernética dos seus círculos de sociabilidade (amigos, família, conhecidos, colegas, etc) o seu complemento.

À intensidade das mostrações, confissões, e partilhas nos diferentes media, corresponde uma maior intensidade psicológica no processo de individualização. Porém, essa individualização parece actualmente não ser levada a cabo em solitário, no espaço recôndito da sua privacidade: a psico-morfologia da experiência social parece agora assumir-se publicamente na revelação da intimidade como modo de afirmação da própria personalidade. A partilha de imagens, vídeos, comentários e opiniões tornados possíveis com as redes sociais online parecem confirmar isso mesmo.

\section{Conclusão}

$\mathrm{Na}$ contemporaneidade, a fundação psicológica e individualista da experiência social mantém-se. Contudo, em vez de contornos narcísicos apresenta uma forma de individualismo que confia na exposição pública de si para se realizar. Há, assim, um trajecto percorrido desde o séc. XIX até ao séc. XXI, no qual os dispositivos tecnológicos de mediação simbólica têm um papel fundamental. Tablets, smartphones, internet são media que exemplificam o quanto a privacidade se imiscui na publicidade.

O homem herdeiro de Narciso pode ser um homem privado; mas é justamente na privacidade do seu computador pessoal, do seu telemóvel ou do seu televisor que ele se torna público e comunica com os seus pares. A privacidade adquire actualmente um novo valor. À sua atomização, ocorrida no séc. XIX e XX, coloca-se agora a hipótese de uma remolecularização com o público. Privacidade e Publicidade registam nas nossas sociedades um novo equilíbrio, ao qual os dispositivos comunicacionais não são alheios. Pelo contrário, é com a emergência dos chamados new media que se desenha uma reformulação da psicomorfologia da experiência social.

De certo modo, o poeta W.H. Auden anuncia já a aproximação do privado e do público afirmando: "Private faces in public places/ Are wiser and nicer/ Than public faces in private places". A nossa utilização dos dispositivos tecnológicos de mediação simbólica parece precisamente corroborá-lo.

\section{REFERÊNCIAS}


Ariès P, Duby G (dir.) (1985), Histoire de la Vie Privée. Paris : Seuil

Arendt, Hannah (2001), A Condição Humana. Lisboa: Relógio d'Água [The Human Condition, Chicago, University of Chicago Press, 1958]

Bauman, Zygmunt (2000), Liquid Modernity. Cambridge: Polity Press

Corbin, Alain (1985), Le Secret de l'Individu, In Ariès et Duby, Tome IV, 1985

Jost, François (2009), La Télé-Réalité. Le Cavalier : Bleu Éditions

Habermas, Jürgen, (1991), The Structural Transformation of the Public Sphere.

Massachusetts: MIT Press [ Strukturwandel der Offentilcheit, Darmstadt, Hemann Luchter Verlag, 1962]

Lipovetsky, Gilles (1989), A Era do Vazio - ensaio sobre o individualismo contemporâneo. Lisboa: Relógio d'Água [L’Ère du Vide, Paris, Gallimard, 1983]

Mannheim, Karl (1978), Diagnóstico de Nuestro Tiempo. México: Fondo de Cultura Económica [Diagnosis of Our Time, London, Routledge\& Kegan Paul, 1943]

Mehl, Dominique (1996), La Télévision de l’Intimité. Paris : Éditions du Seuil

Mateus, Samuel (2013), Tele-Realidade- o princípio de publicidade mediatizado, Covilhã, Livros Labcom (ebook)

Mateus, Samuel (2012), "Reality-Show - uma análise de género", Revista Comunicando, v.1, n. 1

Mateus, Samuel (2010), "Public Intimacy", Sphera Publica, n¹0, La realidad fragmentadaTendencias del discurso mediático, Murcia

Sennett, Richard (1974), The Fall of Public Man. London: Norton \& Company

Tisseron, Serge (2001), L'Intimité Surexposée. Paris : Hachette Littératures

Original recebido em: 07/07/2014

Aceito para publicação em: 28/07/2015

Samuel Mateus é Professor de

Teoria da Comunicação na Universidade da Madeira tendo publicado livros e artigos sobre

temas tão variados quanto publicidade, intimidade, realityshows, opinião pública, modernidade ou individualização. 